\title{
Favourable Functional Outcomes In Idiopathic Inflammatory Myositis- A Single Centre Experience Over 15 Years
}

\section{Ramya Janardana}

St. John's Medical College Hospital

\section{Sangeetha K. N}

St. John's Medical College Hospital

Vasudha Bhat

St. John's Medical College Hospital

\section{Divya Balakrishnan}

St. John's Medical College Hospital John Michael Raj

St. John's Medical College Hospital

Benzeeta Pinto

St. John's Medical College Hospital

\section{Chanakya K}

St. John's Medical College Hospital

\section{Raghunandan Nadig}

St. John's Medical College Hospital

\section{Anita Mahadevan}

NIMHANS

Vineeta Shobha ( $\nabla$ vineeta.s@stjohns.in )

St. John's Medical College Hospital

\section{Research Article}

Keywords: prognostic factors, longitudinal cohort, antisynthetase syndrome

Posted Date: June 21st, 2021

DOI: https://doi.org/10.21203/rs.3.rs-598502/v1

License: (9) (1) This work is licensed under a Creative Commons Attribution 4.0 International License. Read Full License 


\section{Abstract}

Background: To describe the long term clinical outcome and prognostic factors associated with outcome in a longitudinal cohort of idiopathic inflammatory myositis (IIM).

Methods: In this retrospective cohort study, IIM patients were classified as per Bohan and Peter criteria. In those with $\geq 24$ months of followup; treatment response, functional outcomes [health assessment questionnaire-disability index(HAQ-DI) and modified Rankin score(MRS)], Myositis damage index(MDI) at last follow-up was recorded.

Results: The cohort consists of 175 patients, with a mean age of $40.9( \pm 12.6)$ years, M:F 1:3.3; the IIM subsets were dermatomyositis(DM) $78(44.6 \%)$, overlap myositis(OM) 45(25.7\%), antisynthetase syndrome(ASS) $11(6.3 \%)$, polymyositis(PM) $25(14.3 \%)$ and juvenile DM/OM in $15(8.6 \%)$ patients. Mortality rate was $13.4 \%$ and disease related deaths was $9.1 \%$.

Ninety-four patients have followed up for $\geq 24$ months, the median (IQR) of $65(35,100.7)$ months. At last follow-up, $13.8 \%$ were in treatment free remission, $73.4 \%, 11.7 \%$ had complete clinical response and partial clinical response with treatment respectively. HAQ-DI and MRS were favourable in $>90 \%$ of patients. At last follow-up, one-third were off-steroids. Discontinuation of steroids was associated with HAQ-DI of 0 and lower MRS. Complete clinical response on/off medication at last follow-up was associated with HAQ-DI of 0[OR10.9; 95\%CI(3.3,160)], better MRS[OR 3.2; $95 \% \mathrm{Cl}(1.4,7.3)]$ and lesser MDI[OR 1.7; $95 \% \mathrm{CI}(1.1,2.7)]$ at the last follow-up as compared to partial response. Baseline parameters and IIM subsets did not significantly influence outcome.

Conclusion: Our longitudinal cohort of IIM had a good outcome in all major myositis subsets. Partial clinical response on treatment is associated with worse functional outcomes and damage accrual.

\section{Key Messages}

\section{Outcome is favourable with conventional immunomodulatory treatment in majority at a median of 65 months.}

\section{Partial clinical response to treatment is associated with worse functional outcomes and damage accrual.}

\section{Mortality is early and disease related.}

\section{Clinicopathological subsets do not influence outcome.}

\section{Background}

Idiopathic Inflammatory myositis (IIM) are a group of potentially treatable, rare heterogenous chronic systemic autoimmune disorders predominantly affecting the skeletal muscles. A multitude of immunological perturbations contribute to the pathogenesis of myositis, leading to varying severity of not only the myositis but also inflammation of extramuscular organs chiefly lung and skin. ${ }^{1}$

Despite the advances in understanding of immunopathogenesis of IIM, the backbone of treatment for all the subgroups remains almost similar; consisting of glucocorticoids and one or more immunosuppressants. ${ }^{2}$ Considering the heterogeneity of IIM, treatment outcomes have been variable. Similarly, outcome measures and response criteria have been difficult to employ largely due to heterogeneity of IIM and very few large treatment trial results are available to guide clinicians.

Large cohort studies on IIM with long term outcome and its predictors can support and direct research to improve therapeutic results, however these are sparse due to its infrequent occurrence. ${ }^{3-5}$ Moreover, with enhanced understanding of immune mechanisms; the classifications, definitions of clinical phenotype, autoantibody profiling, reporting patterns for muscle biopsy for IIM have undergone immense overhaul in last few decades. Prospective multicentric cohorts have been initiated at various centers in Europe and US, outcome data from them should be available in near future. ${ }^{6}$ Furthermore, there is influence of distinct geographic, ethnic and or environmental factors on the clinical phenotype of IIM, and autoantibody distribution underpinning the need for long term outcome studies across the world. ${ }^{7}$

From Indian subcontinent, the IIM cohorts with long term follow-up are rather sparse. ${ }^{8-13}$ Here, we describe the long term outcome, prognostic factors and mortality data of the IIM subsets over 15 years from our tertiary care referral medical college hospital, India using standard measures of clinical response and patient-reported outcomes. ${ }^{14-18}$

\section{Methods}

\section{Case selection and IIM subgrouping:}


This is a retrospective cohort study, using a structured case record form (CRF); clinical phenotype, treatment administered, follow up and outcomes have been recorded for all consecutive patients of inflammatory myositis from the year 2006 onwards. All patients were classified as definite/probable/possible inflammatory myositis as per Bohan \& Peter criteria. ${ }^{19,20}$ The followup information was updated and extracted till May 2020. As per the current understanding of IIM, patients were re-subgrouped into dermatomyositis (DM), polymyositis (PM), overlap myositis (OM), antisynthetase syndrome (ASS), immune mediated necrotising myositis (IMNM) and clinically amyopathic DM (CADM: includes both amyopathic and hypo myopathic subsets). ${ }^{21-25}$ Juvenile onset myositis (onset < 16 years) were subclassified as juvenile dermatomyositis (JDM) and juvenile polymyositis based on the presence/absence of DM specific rash. Subjects with Inclusion body myositis, muscle dystrophy and metabolic myopathy were excluded. Study was approved by St. John's Medical College Institute Ethics Review Board (Approved No-80/2017).

\section{Disease specific evaluation and assessments:}

Their initial assessments consisted of various descriptors of clinical phenotype including MMT-8, MITAX and dermatologist opinion of cutaneous manifestations. ${ }^{26,27}$ Extramuscular organ assessment was as per clinical indication. Association with malignancy was defined by diagnosis of malignancy within 3 years of onset of myositis. However, diagnosis anytime in the past or at follow-up was recorded. Laboratory assessments include measures of muscle inflammation such as creatine kinase enzyme (CK) level, aspartate aminotransferase (AST) and lactate dehydrogenase (LDH). Autoantibody profile consisted of antinuclear antibody by indirect immunofluorescence, myositis associated antibodies (anti RNP/Sm, anti Ro-60, anti La, anti Ro-52) and anti Jo-1 (myositis specific antibody) as part of EUROIMMUN ANA profile-3 immunoblot assay. In a subset of cohort, EUROIMMUN myoblot was performed which includes anti Mi2, anti SRP, anti aminoacyl t-RNA synthetase antibodies (ARS), anti Pm-Scl and anti Ku. All immunoblot strips were analyzed with the EUROLineScan (Euroimmun) and,+++ or +++ was considered significant. EMG was performed by a neuro physician at our centre. Muscle biopsy was performed in consenting patients and were analysed by neuropathologist at NIMHANS (National Institute of Mental Health and Neurosciences) using hematoxylin and eosin stain, modified Gomori's trichrome stain, periodic acid Schiff (PAS) and immunohistochemistry, as considered appropriate.

\section{Treatment protocols, clinical course and outcome analysis:}

Treatment protocol included methylprednisolone pulse or high dose steroids at $1 \mathrm{mg} / \mathrm{kg}$ body weight for organ threatening disease or respiratory and pharyngeal muscle weakness, while others received steroids equivalent to $0.5 \mathrm{mg} / \mathrm{kg}$ body weight. All patients received immunosuppressive therapy at initial presentation alongside steroids. Steroids were tapered as per physician assessment of improvement of clinical and lab parameters. Course and outcome were analysed for those with 24 or more months of follow up. It was defined as monocyclic, chronic polycyclic and chronic continuous as per Heuber et.al. ${ }^{28}$ Outcomes were recorded as complete/partial clinical response at 6 months and last follow-up, based on physician assessment of muscle power, status of extra muscular features, functional class and laboratory parameters. Complete clinical response was defined as no evidence of active myositis/activity in extramuscular organs for $\geq 6$ months while receiving therapy as determined by treating physician. ${ }^{29}$ Patients not meeting the above definition were grouped into partial clinical response as per the judgement of treating physician. Relapse was recorded in patients with $>6$ months of followup as clinical worsening after a period of improvement. Functional capacity at last follow-up was assessed using 2 patient reported outcome measures; MD-health assessment questionnaire (MD-HAQ) and modified Rankin score(MRS). ${ }^{30,31}$ Damage accrual at last follow up was assessed using Myositis damage index (MDI). ${ }^{26,27}$ Mortality was classified as myositis related if accompanying active illness, significant respiratory weakness, significant infection during initial admission or cancer related.

\section{Statistics:}

Demographic details were represented as frequency (percentage) mean (+/- standard deviation) and median (interquartile range) as appropriate. Chi-square test or Fisher exact test was used to check for association between categorical variables. Association studies for means of continuous variables were evaluated using Student's t-test or Wilcoxon rank sum test as appropriate. Factors associated with complete clinical response, steroid withdrawal and mortality were analysed using logistic regression analysis. Factors found to be significant $(p<0.05)$ in univariate analysis were taken up for multivariate analysis. Survival function was analysed using Kaplan Meier estimation. STATA software version 16 was used for the above analysis, $p$ value was kept at $5 \%$ significance.

\section{Results}

Information from a total of 190 CRFs was extracted. Of them, 15 were excluded due to incomplete information or change in diagnosis at follow up. The cohort consisted of 175 patients, with a mean age of 40.9 years $( \pm 12.6)$ and a female preponderance (F:M::3.3:1). Of the cohort 133/175(76\%) were classifiable as definite/probable IIM as per Peter and Bohan criteria. They were sub-classified as DM 78(44.6\%), OM 45 (25.7\%), ASS 11(6.3\%) and PM 25(14.3\%) and a single case of NAM. In the subset with DM, 5 were CADM. Juvenile onset IIM were 
categorized into juvenile DM (12/15) and juvenile onset OM (3/15). The baseline demographics, disease subsets, autoantibody profile and muscle histopathology features are represented in Table 1. 
Table 1

Baseline demographics, clinical phenotype, autoantibodies, treatment and mortality overview - IIM (overall and subsets).

\begin{tabular}{|c|c|c|c|c|c|c|}
\hline & Overall & DM & OM & PM & JM & ASS \\
\hline \multirow[t]{2}{*}{$\mathbf{N}(\%)$} & 175 & $78(44.6)$ & $45(25.7)$ & 25(14.3) & 15(8.6) & 11(6.3) \\
\hline & & & 20/11/10/4(SSc,MCTD,UCTD,SLE) & & & \\
\hline $\begin{array}{l}\text { Median age in Years } \\
\text { (IQR) }\end{array}$ & $38(27.5,48.5)$ & $39.5(30,50)$ & $37(34,44)$ & $45(29.5,50)$ & $12.5(10,15)$ & $46(43,55)$ \\
\hline F:M & 3.3:1 & 2.9: 1 & $6.5: 1$ & 3.2:1 & $2: 1$ & $1.2: 1$ \\
\hline $\begin{array}{l}\text { Median(IQR) duration } \\
\text { of illness(months) }\end{array}$ & $4(1,7)$ & $3(1,8)$ & $4(1,5)$ & $4(1,6)$ & $2(1,6)$ & $3(2,14.5)$ \\
\hline $\begin{array}{l}\text { Median MMT-8 } \\
\text { (baseline) } n=133\end{array}$ & $61(49,69)$ & $61(50,67)$ & $61(49,72)$ & $55(39,61)$ & $61.5(45.5,71)$ & $66(61.5,75)$ \\
\hline $\begin{array}{l}\text { MITAX (baseline) } n= \\
75\end{array}$ & $12(7,16)$ & $12.5(7,18)$ & $12(6.75,12)$ & $9(5,12)$ & $13(8.5,15.5)$ & 0 \\
\hline Dysphagia (\%) & $51(29.1)$ & $27(34.6)$ & $14(31.1)$ & $6(24)$ & $3(20)$ & 0 * \\
\hline Dysphonia (\%) & $14(8)$ & $5(6.4)$ & $4(8.8)$ & $2(8)$ & $2(13.3)$ & 0 \\
\hline $\begin{array}{l}\text { Respiratory } \\
\text { weakness(\%) }\end{array}$ & $6(3.4)$ & $2(2.5)$ & $4(8.8)$ & 0 & 0 & 0 \\
\hline ILD (\%) & $24(13.7)$ & $6(7.7)$ & $10(22.2)^{\star}$ & $1(2.4)$ & $1(6.6)$ & $6(54.5) * \star *$ \\
\hline DM specific rash(\%) & $70(40)$ & $54(69.2)$ & $3(6.6)$ & $1(2.4)$ & $10(66.6)$ & $2(18.2)$ \\
\hline Cardiac (\%) & $11(6.3)$ & $1(1.3)$ & $6(13.3)^{*}$ & 0 & $1(6.6)$ & $3(27.3) \star \star$ \\
\hline Calcinosis (\%) & $13(7.4)$ & $5(6.4)$ & $2(4.4)$ & $1(2.4)$ & $3(20)$ & $2(18.2)$ \\
\hline Malignancy (\%) & $7(4)$ & $6(7.7)$ & 0 & $1(2.4)$ & 0 & 0 \\
\hline ANA $(n=154)(\%)$ & $98(63.6)$ & $28(38.9)$ & $34(87)$ & $10(41.6)$ & $9(60)$ & $8(80)$ \\
\hline MSA $(n=111)(\%)$ & $12(10.8)$ & $2(4.4)$ & - & $1(6.6)$ & $1(7.6)$ & $8(72.7)$ \\
\hline Jo-1 & $8(7.2)$ & $4(8.8)$ & - & $1(6.6)$ & - & $3(27.2)$ \\
\hline Non Jo-1 ARS & $10(9)$ & $8(17)$ & $1(4.3)$ & - & $1(7.6)$ & - \\
\hline $\mathrm{Ml}-2(\alpha \& \beta)$ & $3(2.7)$ & $1(2.2)$ & $2(8.6)$ & - & - & - \\
\hline \multicolumn{7}{|l|}{ SRP } \\
\hline MAA $(n=137)(\%)$ & $41(29.9)$ & $9(16.3)$ & $25(62.5)^{\star \star}$ & $5(26.3)$ & $2(15.4)$ & 0 \\
\hline U1RNP & $50(36.5)$ & $14(25.4)$ & $22(55)^{\#}$ & $4(21)$ & $3(23)$ & $7(63)^{\star *}$ \\
\hline Ro-52 & $7(6.3)$ & $3(5.4)$ & $3(7.5)$ & $1(5.2)$ & - & - \\
\hline $\mathrm{Ku}$ & $10(9)$ & $4(7.2)$ & $2(5)$ & $1(5.2)$ & $3(23)$ & - \\
\hline Pm-Scl & $5(3.6)$ & $1(1.8)$ & $4(10)$ & - & - & - \\
\hline Scl 70 & $9(6.5)$ & $2(3.6)$ & $2(5)$ & $3(15.7)$ & $2(15.4)$ & - \\
\hline SSA & $4(2.9)$ & $2(3.6)$ & $2(5)$ & - & - & _- \\
\hline CENP & & & & & & \\
\hline $\begin{array}{l}\text { Muscle } \\
\text { Histopathology }\end{array}$ & $n=77$ & $n=34$ & $n=14$ & $n=14$ & $n=8$ & $n=4$ \\
\hline
\end{tabular}

Statistically significant- ${ }^{*} \mathrm{p}=.03$ (ASS vs rest \& OM vs rest); $\#-.01$ (OM vs rest); ${ }^{* \star} \mathrm{p}=.02$ (ASS vs rest \& OM vs rest);*** $\mathrm{p}=.001$ (ASS vs rest).

DM- Dermatomycosis, PM - polymyositis, OM - overlap myositis, SSc- systemic sclerosis, MCTD - Mixed connective tissue disease, UCTD undifferentiated CTD, SLE - systemic lupus erythematosus, ASS- antisynthetase syndrome, JM- Juvenile Myositis, ILD- Interstitial Lung Disease, MMT8- Manual Muscle Testing, MITAX- myositis intention to treat activity index, PFA - Perifascicular atrophy, HCQ-

Hydroxychloroquine, PLEX-Plasma Exchange, IVIg- Intravenous Immunoglobulin, MP- Methylprednisolone 


\begin{tabular}{|c|c|c|c|c|c|c|}
\hline & Overall & DM & OM & PM & $\mathrm{JM}$ & ASS \\
\hline PFA & 22 & 16 & 2 & 0 & 4 & 0 \\
\hline \multirow{2}{*}{$\begin{array}{l}\text { Endomysial } \\
\text { inflammation }\end{array}$} & 3 & 1 & 0 & 1 & 0 & 1 \\
\hline & 44 & 21 & 8 & 9 & 4 & 2 \\
\hline $\begin{array}{l}\text { Perivascular } \\
\text { inflammation }\end{array}$ & 29 & 14 & 8 & 4 & 2 & 0 \\
\hline Necrosis & 4 & 0 & 1 & 1 & 1 & 1 \\
\hline \multicolumn{7}{|l|}{$\begin{array}{l}\text { No features of } \\
\text { myositis }\end{array}$} \\
\hline Treatment & $165(94.2)$ & 75(96.1) & $45(100)$ & $22(88)$ & 12(80) & $10(90.9)$ \\
\hline Steroid & $58(33)$ & $27(34.6)$ & $13(28.8)$ & $8(32)$ & $5(33.3)$ & $5(45.4)$ \\
\hline MP pulse & $90(52)$ & $40(51.2)$ & $26(57.7)$ & $8(32)$ & $10(66.6)$ & $6(54.5)$ \\
\hline Immunosuppressants & $52(29.7)$ & $24(30.7)$ & $17(37.7)$ & $8(32)$ & $2(13.3)$ & $1(9)$ \\
\hline Methotrexate & $33(18.9)$ & $13(16.6)$ & $9(20)$ & $5(20)$ & $2(13.3)$ & $4(36.3)$ \\
\hline Azathioprine & $12(6.8)$ & $5(6.4)$ & $4(8)$ & $1(4)$ & - & $2(18.2)$ \\
\hline \multirow{3}{*}{$\begin{array}{l}\text { Mycophenolate } \\
\text { mofetil } \\
\text { Cyclophosphamide }\end{array}$} & $19(10.8)$ & $8(10.2)$ & $5(11)$ & - & $1(6.6)$ & $5(45.4)$ \\
\hline & $28(16)$ & $13(16.6)$ & $9(20)$ & - & $3(20)$ & $3(27.2)$ \\
\hline & $7(4)$ & $2(2.5)$ & $3(6.6)$ & - & $1(6.6)$ & $1(9)$ \\
\hline Rituximab & $4(2.2)$ & $1(1.2)$ & $2(4.4)$ & - & - & $1(9)$ \\
\hline $\begin{array}{l}\text { HCQ } \\
\text { Tacrolimus }\end{array}$ & $4(2.3)$ & $3(3.8)$ & - & $1(4)$ & - & - \\
\hline \multicolumn{7}{|l|}{ Leflunomide } \\
\hline \multicolumn{7}{|l|}{ IVlg } \\
\hline \multicolumn{7}{|l|}{ PLEX } \\
\hline Death & $24(13.7)$ & 15(19.2) & $2(4.4)$ & $4(16)$ & 2(13.3) & $1(9)$ \\
\hline \multicolumn{7}{|c|}{ 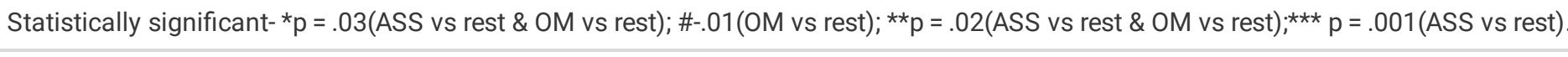 } \\
\hline \multicolumn{7}{|c|}{$\begin{array}{l}\text { DM- Dermatomycosis, PM - polymyositis, OM - overlap myositis, SSc- systemic sclerosis, MCTD - Mixed connective tissue disease, UCTD } \\
\text { undifferentiated CTD, SLE - systemic lupus erythematosus, ASS- antisynthetase syndrome, JM- Juvenile Myositis, ILD- Interstitial Lung } \\
\text { Disease, MMT8- Manual Muscle Testing, MITAX- myositis intention to treat activity index, PFA - Perifascicular atrophy, HCQ- } \\
\text { Hydroxychloroquine, PLEX-Plasma Exchange, IVIg- Intravenous Immunoglobulin, MP- Methylprednisolone }\end{array}$} \\
\hline
\end{tabular}

Myositis autoantibodies:

Antinuclear antibody was detected in 98(57.25\%). MSAs were demonstrated in 26/111(23.4\%), most commonly Jo-1 12/137(8.8\%), Mi-2 10/111(9\%), non Jo-1 ARS 8/111(7.2\%) and SRP 3/111(2.7\%). MAAs were detected in 81/137(59.1\%) while 16(11.7\%) were negative for both MSA \& MAA. Multiple MSA positivity was seen in 6/111(5.4\%), overlap of MSA and MAA was noted in 11/111 (9.9\%). These have been detailed in Table 1.

Clinical response and functional outcome 
Table 2

Outcome parameters at $>24$ months of follow up in IIM subsets $(n=94)$

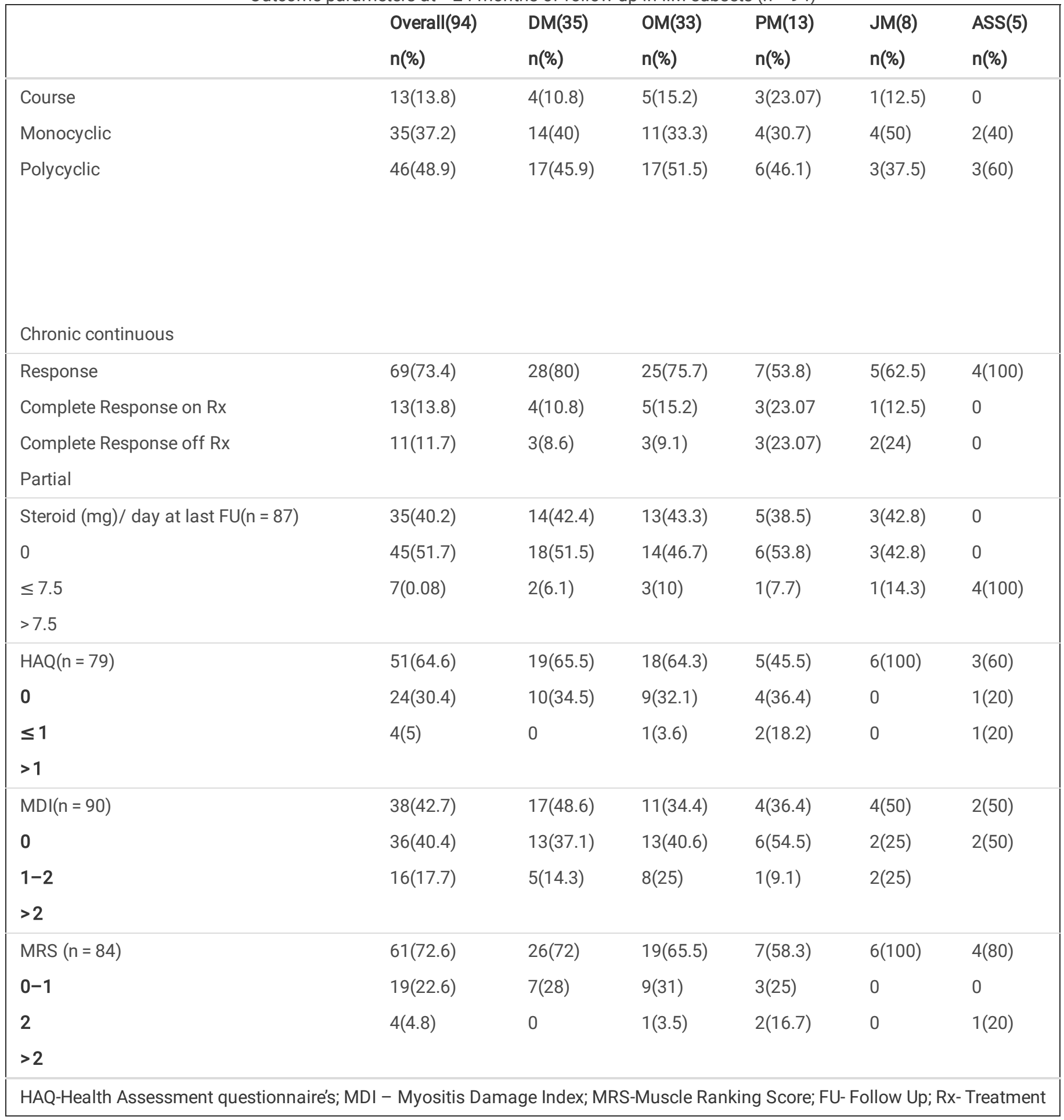


Table 3

Prognostic factors for clinical response, steroids discontinuation and mortality

\begin{tabular}{|c|c|c|c|c|c|}
\hline Prognostic factors for clinical response, steroid withdrawal and death & n & $\begin{array}{l}\text { Odds ratio(95\% } \\
\mathrm{Cl})\end{array}$ & $\begin{array}{l}P \\
\text { value }\end{array}$ & $\begin{array}{l}\text { Adjusted odds } \\
(95 \% \mathrm{Cl})\end{array}$ & $P$ value \\
\hline \multicolumn{6}{|l|}{ CR on or off $\operatorname{Rx}(n=93)$} \\
\hline No Relapses & 93 & $4.9(1.2,19.8)$ & 0.02 & $12.9(0.9,188)$ & 0.06 \\
\hline $\mathrm{HAQ} \leq 1$ at last $\mathrm{f} / \mathrm{u}$ & 76 & $10.9(3.3,160)$ & 0.008 & $6.7(0.8,51.8)$ & 0.06 \\
\hline MRS & 90 & $3.2(1.4,7.3)$ & 0.004 & $1.7(0.4,6.6)$ & 0.4 \\
\hline MDI & 90 & $1.7(1.1,2.7)$ & 0.01 & $1.7(0.9,2.9)$ & 0.07 \\
\hline \multicolumn{6}{|l|}{ Steroid withdrawal $(n=93)$} \\
\hline Myositis associated antibody & 67 & $5.7(1.8,17.4)$ & 0.002 & $4.6(0.69,30.6)$ & 0.14 \\
\hline Ro 52 & 69 & 3.2(1.1,9.5) & 0.03 & $1(0.14,6.9)$ & 0.9 \\
\hline Follow-up duration & 93 & $0.9(0.96,0.99)$ & 0.001 & $0.9(0.96,0.99)$ & 0.02 \\
\hline $\mathrm{HAQ}<=1$ at last $\mathrm{f} / \mathrm{u}$ & 76 & $3.3(1.3,8.6)$ & 0.01 & $1.8(0.2,14.7)$ & 0.5 \\
\hline MRS at last $f / u$ & 80 & $1.7(1,3)$ & 0.03 & $1.2(0.3,4.7)$ & 0.7 \\
\hline \multicolumn{6}{|l|}{ Mortality $(n=175)$} \\
\hline DM vs non DM & & $2.52(0.9,6.3)$ & 0.052 & & \\
\hline Baseline MMT-8 & 131 & $0.97(0.93,1)$ & 0.05 & $0.9(0.9,1.1)$ & 0.1 \\
\hline Dysphagia & & $2.5(1.03,6.2)$ & 0.04 & $1.5(0.3,6.8)$ & 0.6 \\
\hline Dysphonia & & $5.3(1.6,17)$ & 0.005 & $3.4(0.3,35.8)$ & 0.3 \\
\hline Respiratory weakness & & $6.3(1.8,22)$ & 0.004 & $2.5(0.2,28.3)$ & 0.4 \\
\hline Malignancy & & $6(1.9,18.3)$ & 0.002 & $1.5(0.2,10.5)$ & 0.7 \\
\hline RNP/Sm positivity & 140 & $0.12(0.02,0.9)$ & 0.002 & $0.1(0.02,1.2)$ & 0.07 \\
\hline \multicolumn{6}{|c|}{$\begin{array}{l}\text { Factors analysed in univariate analysis were age, sex, diagnosis, time to presentation, baseline MMT-8, oropharyngeal weakness, ILD, MSA } \\
\text { positivity, MAA positivity, Ro-52positivity, RNP/Sm positivity, time to } 0-15 \mathrm{mg} / \mathrm{kg} \text { steroids, response at } 6 \text { months, relapsing disease, HAQ- } \\
\text { DI ,MRS,MDI at last follow-up. Significant factors ( } \mathrm{p}=<0.05 \text { ) only are represented in the table. }\end{array}$} \\
\hline $\begin{array}{l}\text { DM- Dermatomycosis, MMT8- Manual Muscle Testing, MRS-Muscle } \\
\text { Hydroxychloroquine, CR-Complete Response }\end{array}$ & & re, MITAX- n & & & , HCQ- \\
\hline
\end{tabular}

Steroids were used in all patients except one, the majority [157(89.7\%)] required high dose steroids, 58/175 (33.1\%) required pulse steroids in addition. All patients received simultaneous steroid sparing agents. The distribution of steroid sparing immunomodulators are represented in Table 1. Median number of steroid sparing immunomodulators used in management of these patients were 1 $(1,2)$. Methotrexate was the most common immunomodulator prescribed in $91(52 \%)$ of patients. Nineteen $(10.9 \%)$ patients in this cohort required rituximab due to either relapse or lack of adequate response to steroids and or steroid sparing immunomodulators.

Follow up information of 24 months or more was available in 94 (54.9\%) patients, the median (IQR) followup in this subset was 65(35,100.7) months. Of them, $13(13.8 \%)$ had monocyclic illness (treatment free remission), $37(38.5 \%)$ polycyclic and $46(47.9 \%)$ chronic continuous course. At the last follow up, 69(73.4\%) were in complete clinical remission (CR) on medications, $11(11.7 \%)$ had partial response(PR). Overall, complete discontinuation of steroids could be achieved in 35(36.5\%) and another $46(47.9 \%)$ were on low dose prednisolone $<7.5 \mathrm{mg} / \mathrm{day}$. Complete discontinuation of steroids[35(38.9\%)] was associated with a longer follow-up duration(OR 0.9(0.96,0.99)), MAA positivity[OR 5.7(1.8,17.4)]), Ro-52 positivity [(3.2(1.1.9,5)] better HAQ-DI (OR 3.3(1.3,8.6)) and MRS[OR 1.7(1,3)]) scores as compared to those who were on some dose of steroids[52(61.1\%)].

Complete clinical response on/off treatment at last follow-up[82(87.2\%)] were less likely to have a relapse (OR 4.9(1.2,19.8), more likely to have HAQ-DI of 0 at last follow-up[OR 10.9(3.3,160)], better MRS [3.2(1.]4,7.3)), lesser MDI scores[1.7 $(1.1,2.7)]$ ) as compared to those who had partial response[11(11.7\%)] at last follow-up. Treatment free remission was attained by 13(13.8\%) individuals, after a median(IQR) of $60(36,89)$ months; they had a longer median duration of follow-up[OR $0.9(0.97,0.99)]$, were less likely to have dysphagia at presentation [OR 
0.3(0.09,0.9)], were associated with Ro-52 positive [OR $8.5(1,70)$ ]. They had a moderate severity at presentation [median(IQR)MMT 8 of $52.5(50,59)]$, other baseline factors and response and functional outcomes were not different from the rest of the cohort.

Median HAQ score $(n=79)$ recorded at last follow-up was $0(0,0.2)$ and was recorded 0 in $51(63.7 \%)$. Another $24(31.2 \%)$ patients had mild to moderate disability $(\mathrm{HAQ}>0 \leq 1)$ and only 4 reported moderate to severe $(\mathrm{HAQ}>1)$ disability (Fig. 1). Correspondingly, MRS scores (84) were favorable in our cohort with median scores of $0(0,2) ; 61(70.4 \%)$ having no residual symptoms or no significant disability(score-0,1); $19(21.6 \%)$ having slight disability (score-2) and 4(5.7\%) having moderate disability respectively. Median MDI scores of the cohort $(n=89)$ was $1(1,2)$.

In view of the majority having a favourable outcome, factors influencing outcome were not further explored. The common complications observed during followup included infections, metabolic and cardiovascular events. These are represented in supplementary table2.

\section{Relapse:}

Among patients who have followed up for longer than 6 months $(n=125)$, a single relapse has occurred in $45(36 \%)$ while more than one relapse has occurred in $21(16.8 \%)$. Median relapse free survival rate of our cohort is $121(\mathrm{Cl} 88-153)$ months. Survival curve based on relapse free survival is represented in Fig. 2. Factors such as IIM subtype, dysphagia, ILD, MAA, complete vs partial response at 6 months, median HAQ, median MRS and median MDI were not different in the subgroups who had at least one relapse versus those who had no relapse.

\section{Malignancy:}

Association with malignancy was noted in 7 patients (DM-5, CADM-1, PM-1). The median duration between diagnosis of malignancy and myositis was $2.5(0,5)$ months except for a single patient developing malignancy 59 months after diagnosis of myositis. Features of muscle disease / DM skin lesions persisted in 4 even after the treatment of malignancy, requiring steroids and immunomodulatory agents over long term. The malignancies noted were carcinoma of breast (2), papillary carcinoma of thyroid (1), lung carcinoma (2) and adenocarcinoma of $\operatorname{ovary}(2)$.

\section{Mortality:}

In our cohort, 24 (13.7\%) patients have died. Disease specific mortality rate was $9.1 \%$. One year, 5 years and 10 years cumulative survival rate of our cohort was $89.1 \%, 86.9 \%$ and $86.3 \%$ respectively. Majority of deaths $(15 / 24)$ occurred during the initial 6 months of illness and were related to disease $(45.8 \%)$ or infectious complications $(16.6 \%)$. The median duration from diagnosis to death was $3.5(1,10.5)$ months. The mean survival time of the cohort was $239(\mathrm{Cl} 220,258)$ months(Fig. 3).

Acute coronary syndrome (ACS, $n=2$ ) leading to deaths were attributed to IIM both were young ( $<50$ years) and had no other adverse cardiac risk factors. Of the 7 patients with malignancy, 4 have died during follow up. Two were directly related to malignancy and occurred soon after diagnosis itself. Survival curve based on the above data is depicted in Fig. 2. Univariate regression analysis of factors associated with mortality were baseline MMT-8[OR 0.97(0.9,1)], dysphonia[5.3(1.6,17)], dysphagia[2.5(1,6.2)], respiratory weakness[6.3(1.8,22)], malignancy[6(1.9,18.3)], and absence of RNP/Sm[0.1(0.02,0.9)], however none of the factors were found to be significant in multivariate analysis (Table 3).

\section{Discussion}

We present here the largest single centre prospective longitudinal data on inflammatory myositis from the Indian subcontinent in a real-life setting. Clinical phenotype of our cohort is similar to the published reports across the world, however, we report a lower prevalence of extramuscular manifestations(Supplementary table 1).3,11,32,33 Higher female preponderance, lesser mean age in our cohort as compared to EuroMyositis cohort is likely contributed by higher prevalence of OM subset in our cohort, however it is comparable to the other Indian and Chinese cohort. ${ }^{3,11,32}$ Polymyositis proportion(14.3\%) is higher than in other published cohorts, probably attributable to prevalent understanding of IIM at that time. As we have learnt since the discovery of MSA and recognition of MAA, that more and more PM can be classified either as DM or ASS or IMNM or IBM. ${ }^{34}$

\section{Clinical response and functional outcome:}

The induction and maintenance immunosuppressive treatment is in line with other published cohorts. However, the median number of steroid sparing immunomodulatory medications used is less in our cohort as compared to the Euro Myositis cohort. Hallmark of our cohort is discontinuation of steroids in almost one-third of patients and the ability to reduce it to $\leq 7.5 \mathrm{mg} / \mathrm{day}$ prednisone in close to half (47.9\%) of the patients. There are very few studies discussing this matter, however it is comparable to the large Chinese cohort of Xio Ming Shu et.al. ${ }^{3}$ Complete discontinuation of steroids is associated with better HAQ and MRS scores, hence, this target should be pursued in all IIM patients. 
Complete clinical response on or off medication is associated with absence of relapse, better functional outcomes in terms of HAQ-DI and MRS, and reduced damage accrual in our cohort. Relapse related to a refractory disease needs a consideration for revision of the immunomodulatory therapies as a target of complete clinical response needs to be pursued.

Treatment-free remission differs in various cohorts. Treatment free remission was around $20 \%$ in the Netherland cohort, and was not associated with any of the factors studied. ${ }^{31}$ Another Indian Cohort by Ramesha et al. have described a medication free remission in $39 / 68$ (57\%) of their cohort, however their cohort size is much smaller with lesser duration of follow-up. ${ }^{35}$ Treatment free remission in our cohort was $13.8 \%$; it was associated with longer duration of followup, absence of baseline dysphagia and Ro52 positivity. Treatment free remission is a subset which needs a dedicated study in future prospective cohorts.

Significant disability at last follow-up is seen in only < $5 \%$ of patients in our cohort, which is significantly different from the Netherland(24\%) and Hungarian cohorts(47\%). ${ }^{31.36}$ Furthermore, in comparison to the Chinese cohort as well, the median HAQ-DI score in our cohort is lesser even though the number of patients with mild disability is higher, thereby demonstrating overall good outcome. Both the Caucasian cohorts were published a decade and half earlier, the improved outcomes in ours and the Chinese cohort, may be reflective of early referral, better understanding in the management over the last 2 decades. Amongst those who have survived, unless there is a recent relapse (< $10 \%)$, patients have remained quiescent on or off medications, which is similar to the Chinese and Hungarian cohort. 3,36

\section{Mortality:}

Disease specific mortality rate $(9.1 \%)$ in our cohort over a median duration of $26.5(6,72)$ months of follow up is comparable to other large cohorts. 3,31 Mortality rate and etiologies of death varies in various cohorts depending on definition of cause of death, inpatient vs population based mortality data. Majority of deaths (62.5\%) occurred early (<6 months since diagnosis); due to active disease and /or infections. Similar observation has been noted in recent publications from India too. ${ }^{10,15}$

Furthermore, infections as a major cause of mortality has also been highlighted in most large cohorts viz. Chinese, US, Mexico, Japanese, and Spanish (20-60\%) cohorts too. ${ }^{37-40}$ However, it is not a significant cause of mortality in some other cohorts (Hungarian, Swedish and Netherland cohorts), where active disease leading cardiorespiratory involvement and malignancy forms the leading cause of death. ${ }^{39,40}$ Higher infections in our IIM cohort may possibly be related to the intense immunosuppression, during initial management of IIM and the general living conditions of our population. Although factors such as diagnosis of DM, oropharyngeal weakness, MMT-8, respiratory weakness and malignancy were found in association with mortality in univariate analysis in our cohort, none of these factors remained significant in multivariate analysis. Age at onset, malignancy, cardiopulmonary and respiratory muscle involvement appeared as risk factors to death in few cohorts. 3,31,41 Overall, contributing factors for mortality in IIM deserves attention on a larger scale, to ascertain and ameliorate modifiable factors. With more ease of availability of extended autoantibody profiling in IIM, this association may prove to be the most determining factor.

\section{Limitations}

Over the last few decades, understanding of interrelationship between clinical phenotypes, autoantibody associations, immunopathogenesis and therapeutic options for IIM have undergone a substantial transformation. The autoantibody assays and the therapeutic choices have been variable as per prevalent opinions and consensus in this real-life experience cohort. In the subgroup with relapse, structured review of compliance has not been performed. Similarly, in the mortality subgroup, information about terminal events and its treatment is unclear in some.

\section{Conclusions}

IIMs are potentially treatable diseases, requiring long term treatment and follow up. Through our study, we emphasize that good long term functional outcomes as determined by low HAQ, MRS can be achieved in majority. Complete clinical response on /off treatment and discontinuation of steroids is associated with better functional outcomes. Damage accrual is more in those who are unable to achieve complete clinical response with treatment. Infection remains an important cause of early mortality second only to active disease.

\section{Declarations}

Ethics approval and consent to participate: Study is approved by Institutional Ethics Committee St. John's Medical College, St. John's National Academy of Medical Sciences (Approved No-80/2017).

Consent for publication: Yes

Availability of data and materials: The data and materials are available to all authors 
Competing interest: None of the authors has any conflict of interest to disclose.

\section{Funding: None}

\section{Authors Contribution:}

1) Conception and design of the study- Dr.RJ, Dr.VS

2) Analysis and interpretation of data- Dr.RJ, Dr.VS, Mr.JMR

3) Data acquisition - All authors

4) Drafted the work and revised it critically for important intellectual content - Dr.RJ, Dr.VS, Dr.R N, Dr.AM

5) Approved the version to be published- All authors

6) Agree to be accountable for all aspects of the work in ensuring that questions related to the accuracy or integrity of any part of the work are appropriately investigated and resolved- All authors

Ethical Publication: We confirm that we have read the Journal's position on issues involved in ethical publication and affirm that this report is consistent with those guidelines.

Acknowledgements: Physician Research Foundation; Academic wing of Association of Physicians of India provided EUROIMMUN myoblot kits.

\section{References}

1. Schmidt J. Current Classification and Management of Inflammatory Myopathies. J Neuromuscul Dis. 2018;5(2):109-129. doi:10.3233/JND-180308

2. Oddis C V., Aggarwal R. Treatment in myositis. Nat Rev Rheumatol. 2018;14(5):279-289. doi:10.1038/nrrheum.2018.42

3. Shu XM, Lu X, Xie Y, Wang GC. Clinical characteristics and favorable long-term outcomes for patients with idiopathic inflammatory myopathies: A retrospective single center study in China. BMC Neurol. 2011;11(1):143. doi:10.1186/1471-2377-11-143

4. Sultan SM, Ioannou Y, Moss K, Isenberg DA. Outcome in patients with idiopathic inflammatory myositis: Morbidity and mortality. Rheumatology. 2002;41(1):22-26. doi:10.1093/rheumatology/41.1.22

5. Er EG, Zihni FY, Karabulut G, Keser G, Kabasakal Y. SAT0338 Survival in a turkish inflammatory myositis cohort: a single-centre study. In: Annals of the Rheumatic Diseases. Vol 76. BMJ; 2017:899.3-900. doi:10.1136/annrheumdis-2017-eular.5956

6. Rider LG, Dankó K, Miller FW. Myositis registries and biorepositories: Powerful tools to advance clinical, epidemiologic and pathogenic research. Curr Opin Rheumatol. 2014;26(6):724-741. doi:10.1097/BOR.0000000000000119

7. Aguilar-Vazquez A, Chavarria-Avila E, Pizano-Martinez O, et al. Geographical Latitude Remains as an Important Factor for the Prevalence of Some Myositis Autoantibodies: A Systematic Review. Front Immunol. 2021;12:1. doi:10.3389/fimmu.2021.672008

8. Khadilkar S, Patil S, Amin S. Study of idiopathic inflammatory myopathies with special reference to borderland between idiopathic inflammatory myopathies and muscular dystrophies. Neurol India. 2008;56(3):356-362. doi:10.4103/0028-3886.43456

9. Prasad ML, Sarkar C, Roy S, et al. Idiopathic inflammatory myopathy: Clinicopathological observations in the indian population. Rheumatology. 1992. doi:10.1093/rheumatology/31.12.835

10. Muhammed H, Gupta L, Zanwar AA, et al. Infections Are Leading Cause of In-Hospital Mortality in Indian Patients With Inflammatory Myopathy. JCR J Clin Rheumatol. 2019. doi:10.1097/rhu.0000000000001214

11. Porkodi R, Shanmuganandan K, Parthiban M, Madhavan R, Rajendran P. Clinical spectrum of inflammatory myositis in South India - A ten year study. J Assoc Physicians India. 2002.

12. Challa S, Hui M, Jakati S, et al. Juvenile idiopathic inflammatory myopathies: A clinicopathological study with emphasis on muscle histology. Indian J Pathol Microbiol. 2019. doi:10.4103/IJPM.IJPM_387_17

13. Prasad S, Misra R, Agarwal V, Lawrence A, Aggarwal A. Juvenile dermatomyositis at a tertiary care hospital: Is there any change in the last decade? Int J Rheum Dis. 2013. doi:10.1111/1756-185X.12053

14. Kulkarni N, Venugopalan A, Saluja M, Chopra A. AB0585 SINGLE CENTER EXPERIENCE OF CLINICAL PROFILE OF INFLAMMATORY MYOSITIS FROM INDIA. Ann Rheum Dis. 2020;79(Suppl 1):1590.2-1590. doi:10.1136/annrheumdis-2020-eular.5768 
15. Mehta P, Agarwal V, Gupta L. High early mortality in idiopathic inflammatory myopathies: results from the inception cohort at a tertiary care centre in northern India. Rheumatology. January 2021. doi:10.1093/rheumatology/keab001

16. Naveen R, Rathore U, Agarwal V, Gupta L. Characteristics and outcomes of overlap myositis: a comparative multigroup cohort study in adults from the MyoCite cohort. Rheumatol Int. 2021;41(3):551-563. doi:10.1007/s00296-020-04779-y

17. Liza Rajasekhar, Vineeta Shobha, Anitha Narasimhan et.al Prevalence and Clinical Correlates of Myositis Specific Autoantibodies in Idiopathic Immune-Mediated Inflammatory Myositis - Results from a Multicentric Cohort (MyolN) from India. J Assoc Physicians India, Vol. 69, January 2021 (preprint)

18. Pinto B, Janardana R, Nadig R, et al. Comparison of the 2017 EULAR/ACR criteria with Bohan and Peter criteria for the classification of idiopathic inflammatory myopathies. Clin Rheumatol. 2019;38(7). doi:10.1007/s10067-019-04512-6

19. Bohan A, Peter J. Bohan A, Peter J. Polymyositis and dermatomyositis. N Engl J Med. 1975. doi:10.1056/NEJM197502202920807

20. Bohan A, Peter JB. Polymyositis and dermatomyositis (first of two parts). N Engl J Med. 1975. doi:10.1056/NEJM197502132920706

21. Lundberg IE, Tjärnlund A, Bottai M, et al. 2017 European League Against Rheumatism/American College of Rheumatology classification criteria for adult and juvenile idiopathic inflammatory myopathies and their major subgroups. In: Annals of the Rheumatic Diseases. Vol 76. Ann Rheum Dis; 2017:1955-1964. doi:10.1136/annrheumdis-2017-211468

22. Allenbach Y, Mammen AL, Benveniste O, et al. 224th ENMC International Workshop:: Clinico-sero-pathological classification of immunemediated necrotizing myopathies Zandvoort, The Netherlands, 14-16 October 2016. Neuromuscul Disord. 2018;28(1):87-99. doi:10.1016/j.nmd.2017.09.016

23. Senécal JL, Raynauld JP, Troyanov Y. Editorial: A New Classification of Adult Autoimmune Myositis. Arthritis Rheumatol. 2017;69(5):878884. doi:10.1002/art.40063

24. Troyanov Y, Targoff IN, Tremblay JL, Goulet JR, Raymond Y, Senécal JL. Novel classification of idiopathic inflammatory myopathies based on overlap syndrome features and autoantibodies: Analysis of 100 French Canadian patients. Medicine (Baltimore). 2005;84(4):231-249. doi:10.1097/01.md.0000173991.74008.b0

25. Gerami P, Schope JM, McDonald L, Walling HW, Sontheimer RD. A systematic review of adult-onset clinically amyopathic dermatomyositis (dermatomyositis siné myositis): A missing link within the spectrum of the idiopathic inflammatory myopathies. $J$ Am Acad Dermatol. 2006. doi:10.1016/j.jaad.2005.10.041

26. Rider LG, Aggarwal R, MacHado PM, et al. Update on outcome assessment in myositis. Nat Rev Rheumatol. 2018. doi:10.1038/nrrheum.2018.33

27. Rider LG, Werth VP, Huber AM, et al. Measures of adult and juvenile dermatomyositis, polymyositis, and inclusion body myositis. Arthritis Care Res. 2011;63(SUPPL. 11):118-157. doi:10.1002/acr.20532

28. Huber AM, Lang B, LeBlanc CMA, et al. Medium- and long-term functional outcomes in a multicenter cohort of children with juvenile dermatomyositis. Arthritis Rheum. 2000;43(3):541-549.

29. Oddis C V., Rider LG, Reed AM, et al. International consensus guidelines for trials of therapies in the idiopathic inflammatory myopathies. Arthritis Rheum. 2005;52(9):2607-2615. doi:10.1002/art.21291

30. Neri R, Mosca M, Stampacchia G, et al. Functional and isokinetic assessment of muscle strength in patients with idiopathic inflammatory myopathies. Autoimmunity. 2006. doi:10.1080/08916930600623817

31. Bronner IM, Van Der Meulen MFG, De Visser M, et al. Long-term outcome in polymyositis and dermatomyositis. Ann Rheum Dis. 2006;65(11):1456-1461. doi:10.1136/ard.2005.045690

32. Lilleker JB, Vencovsky J, Wang G, et al. The EuroMyositis registry: An international collaborative tool to facilitate myositis research. Ann Rheum Dis. 2018;77(1):30-39. doi:10.1136/annrheumdis-2017-211868

33. Chinniah KJ, Mody GM. The spectrum of idiopathic inflammatory myopathies in South Africa. Clin Rheumatol. 2020. doi:10.1007/s10067-020-05048-w

34. Mariampillai K, Granger B, Amelin D, et al. Development of a New Classification System for Idiopathic Inflammatory Myopathies Based on Clinical Manifestations and Myositis-Specific Autoantibodies. JAMA Neurol. 2018. doi:10.1001/jamaneurol.2018.2598

35. Ramesha KN, Kuruvilla A, Sarma PS, Radhakrishnan V V. Clinical, electrophysiologic, and histopathologic profile, and outcome in idiopathic inflammatory myositis: An analysis of 68 cases. Ann Indian Acad Neurol. 2010. doi:10.4103/0972-2327.74190

36. Ponyi A, Borgulya G, Constantin T, Váncsa A, Gergely L, Dankǒ K. Functional outcome and quality of life in adult patients with idiopathic inflammatory myositis. Rheumatology. 2005. doi:10.1093/rheumatology/keh404

37. Murray SG, Schmajuk G, Trupin L, et al. A population-based study of infection-related hospital mortality in patients with dermatomyositis/polymyositis. Arthritis Care Res. 2015;67(5):673-680. doi:10.1002/acr.22501 
38. Ishizuka M, Watanabe R, Ishii T, et al. Long-term follow-up of 124 patients with polymyositis and dermatomyositis: Statistical analysis of prognostic factors. Mod Rheumatol. 2016;26(1):115-120. doi:10.3109/14397595.2015.1054081

39. Galindo-Feria AS, Rojas-Serrano J, Hinojosa-Azaola A. Clinical and prognostic factors associated with survival in Mexican patients with idiopathic inflammatory myopathies. J Clin Rheumatol. 2016;22(2):51-56. doi:10.1097/RHU.0000000000000365

40. Nuño-Nuño L, Joven BE, Carreira PE, et al. Mortality and prognostic factors in idiopathic inflammatory myositis: a retrospective analysis of a large multicenter cohort of Spain. Rheumatol Int. 2017;37(11):1853-1861. doi:10.1007/s00296-017-3799-x

41. Dankó K, Ponyi A, Constantin T, Borgulya G, Szegedi G. Long-Term Survival of Patients with Idiopathic Inflammatory Myopathies According to Clinical Features: A Longitudinal Study of 162 Cases. Medicine (Baltimore). 2004;83(1):35-42. doi:10.1097/01.md.0000109755.65914.5e

\section{Figures}

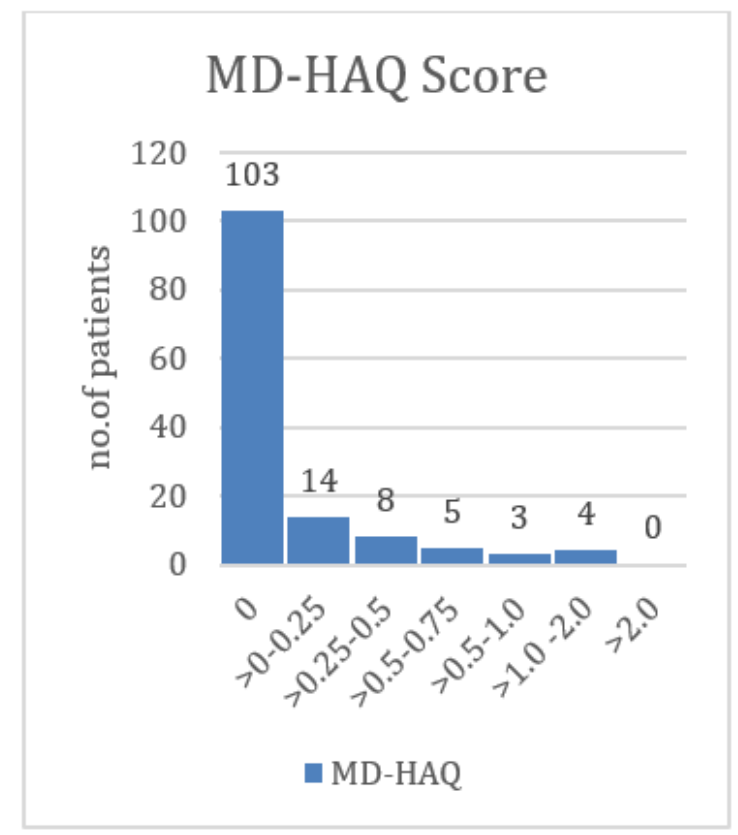

\section{Figure 1}

MD- HAQ score at last follow up 


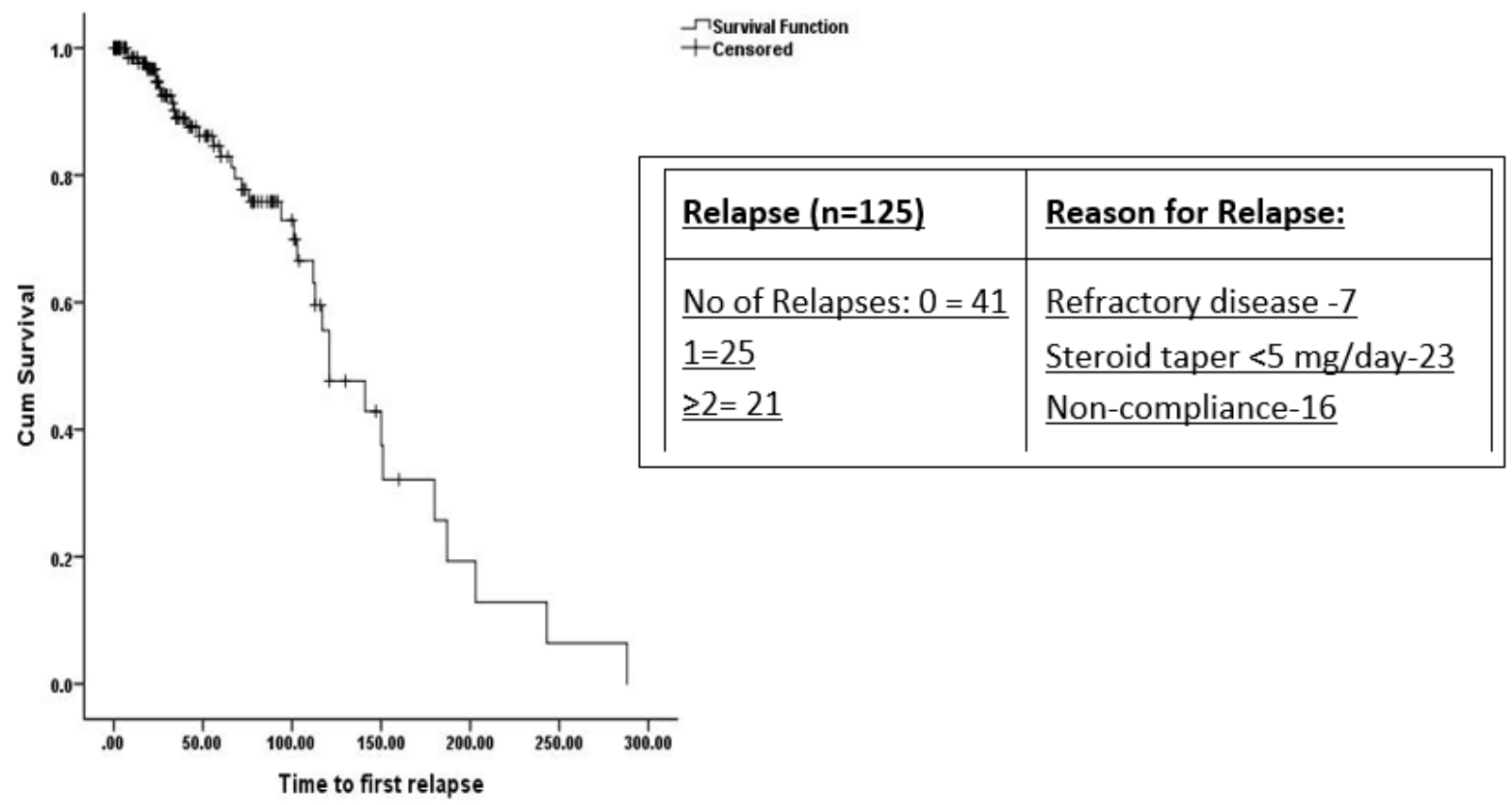

Median relapse free survival of the cohort is 121 (CI 88-153) months

Figure 2

Relapse free survival curve

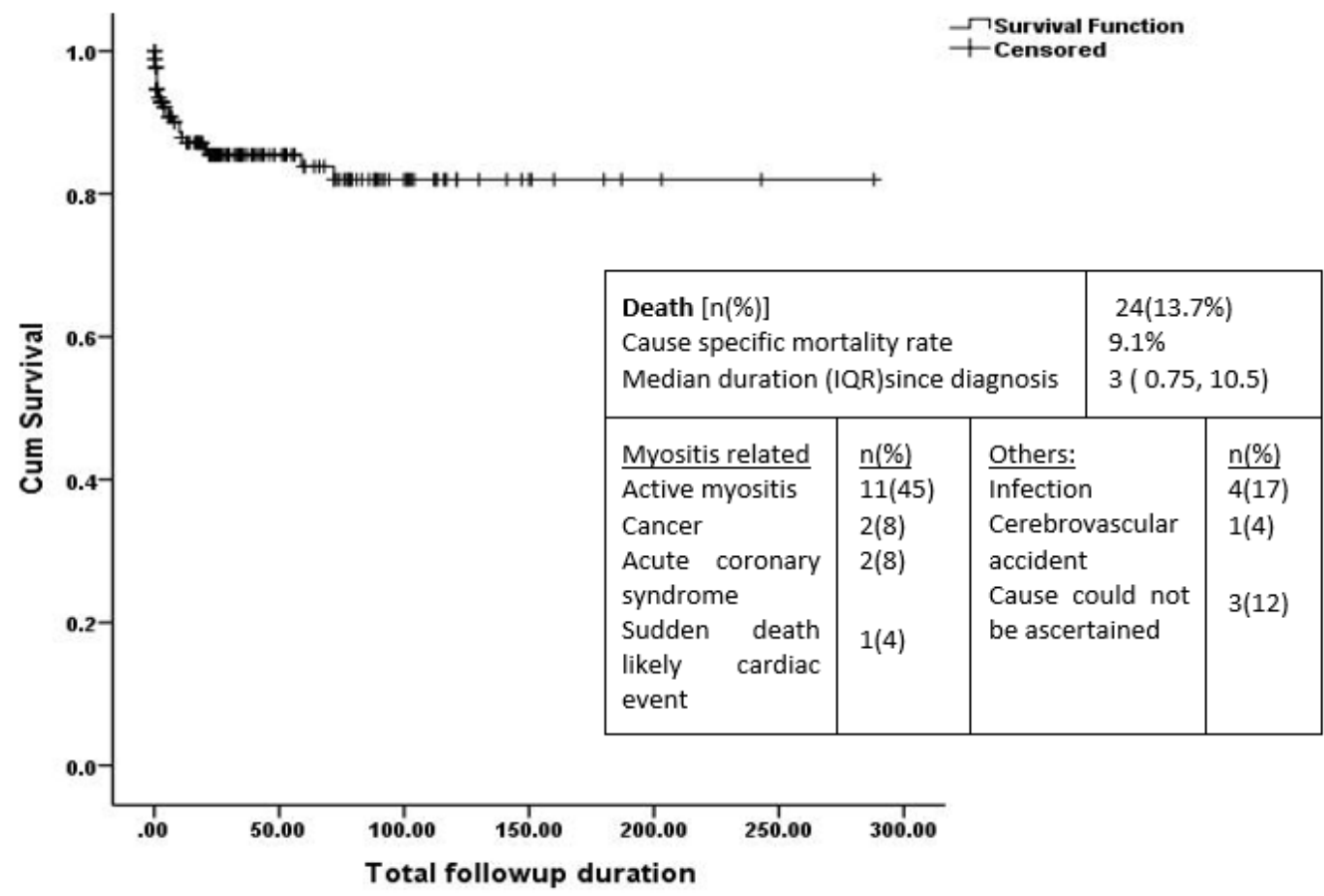

Mean survival time of cohort $=239$ (CI 220,258) months.

Figure 3

Cumulative survival curve of the cohort 
This is a list of supplementary files associated with this preprint. Click to download.

- SupplementaryTable.docx

Page 15/15 